\title{
Effects of climate change on international tourism
}

\author{
Jacqueline M. Hamilton' ${ }^{1}$, David J. Maddison ${ }^{2}$, Richard S. J. Tol ${ }^{1,3,4, *}$ \\ ${ }^{1}$ Research Unit Sustainability and Global Change, Hamburg University and Centre for Marine and Atmospheric Science, \\ Bundesstrasse 55, 20146 Hamburg, Germany \\ ${ }^{2}$ Department of Economics, University College, Gower Street, London WC1E GBT, UK \\ ${ }^{3}$ Institute for Environmental Studies, Vrije Universiteit, De Boelelaan 1081, Amsterdam, The Netherlands \\ ${ }^{4}$ Department of Engineering and Public Policy, Carnegie Mellon University, Baker Hall 129, Pittsburgh, Pennsylvania 15213, USA
}

\begin{abstract}
We present a simulation model of the flow of tourists between 207 countries, used to study the impact of climate change on international tourism. The model almost perfectly reproduces the calibration year 1995, and performs well in reproducing the observations for 1980, 1985 and 1990. The model is used to generate scenarios of international tourist departures and arrivals for the period 2000-2075, with particular emphasis on climate change; we report variations on a single baseline scenario (A1B). The growth rate of international tourism is projected to increase over the coming decades, but may slow down later in the century, as demand for travel saturates. Emissions of carbon dioxide would increase quickly as well. With climate change, preferred destinations would shift to higher latitudes and altitudes. Tourists from temperate climates would spend more holidays in their home countries. As such tourists currently dominate the international tourism market, climate change would decrease worldwide tourism. Nevertheless, its effects are small compared to the baseline projections of population and economic growth.
\end{abstract}

KEY WORDS: International tourism $\cdot$ Climate change impacts $\cdot \mathrm{CO}_{2}$ emissions $\cdot$ Scenarios

\section{INTRODUCTION}

Climate is one of the main drivers of international tourism, as the majority of tourists seek to relax in the sun or the snow (Aguiló et al. 2005). We used the definition in WTO (2003), according to which a tourist spends at least 1 but not more than 364 nights away from home; an international tourist crosses an international border. This study does not consider domestic tourism, and for simplicity we refer to 'international tourism' simply as 'tourism'. The data exclude business travel, and groups together pleasure travel with travel for family visits, pilgrimage, education, and health.

Climate plays only a minor role in the tourism literature (e.g. Witt \& Witt 1995), perhaps because its importance is so self-evident, or perhaps because climate is believed to be constant or beyond control. Climate, however, is changing and likely to continue to change for decades to come. Climate change would substan- tially affect tourism, something that is largely ignored in the literature on climate change impacts (e.g. Smith et al. 2001, Scott et al. 2004), even though tourism is now the largest industry in the world and is still growing quickly. Tourism has a strong impact on the environment (Goessling 2002), and a substantial impact on climate, not just through the emissions of $\mathrm{CO}_{2}$ (particularly from air travel), but also through the direct impact of flying (e.g. contrails).

One can approach the relationship between tourism and climate (change) in 2 different ways, by looking: (1) at tourists, what they (should) prefer (e.g. Scott \& McBoyle 2001, Amelung \& Viner in press) or how they behave (e.g. Maddison 2001, Richardson \& Loomis 2004); or (2) at destinations and how their attractiveness changes with climate and management (e.g. Abegg 1996, Craig-Smith \& Ruhanen 2005, Perry 2005). Reviews of the climate and tourism literature are given by Hamilton \& Tol (2004) and Scott et al. (2005). 
However, looking at a particular group of tourists or a particular destination is not enough to fully understand tourist behaviour. Tourism, like any market, is defined by supply and demand, by push and pull factors. Destinations compete for the most lucrative tourists, and tourists compete for the best deals. A necessary component in the study of tourism is a comprehensive model of tourists and destinations. For international tourism, this implies a global model.

We built on a recent study by Hamilton et al. (2005) where the first version of the Hamburg Tourism Model (HTM) was presented: an econometric simulation model of the travel patterns of tourists from 207 countries, enjoying their holidays in one of the other 206 countries. The model finds that climate change affects international tourism, but that this effect is small compared to the other changes in the industry, such as those due to population growth and change in per capita income. Hamilton et al. (2005) found that locations that are cool at present would attract more tourists under global warming, and that currently warm places would attract fewer tourists. Changes in the strength of the pull effect of international destinations, however, are tempered by changes in the strength of the push effect of the home country. Tourists from places that are temperate (warm) at present would increasingly spend their holiday in their home country, not abroad. As tourists from the temperate countries of West Europe dominate the market, total international tourism numbers would fall (relative to a rapidly rising baseline without climate change), and so would total distance travelled.

In this study, we extended the HTM by: (1) taking a closer look at its ability to predict observations that were not used in the calibration, which leads to a few adjustments in the parameterisation; (2) using higher income elasticities, but allowing demand to saturate; (3) estimating emissions of $\mathrm{CO}_{2}$ from international tourism for various scenarios; (4) studying the implications of changes in international tourism for domestic tourism.

Section 2 presents the model, its calibration and its validation. The model and all necessary input data can be downloaded at www.uni-hamburg.de/Wiss/FB/15/ Sustainability/HTM11.zip. Section 3 presents analyses based on scenarios of climate, population and income. Sensitivity analyses are presented in Section 4. Section 5 summarizes the conclusions of this study.

\section{THE MODEL}

We used HTM version 1.1, which models tourist flows between 207 countries. The purpose of the HTM is not to understand the current pattern of interna- tional tourism-for that, we would need a more detailed description of tourist behavior than is available to us - but rather to analyse how the current pattern may change under not implausible scenarios of future population growth, economic growth and, particularly, climate change. The inputs to the patterns and their changes are the empirical regularities reported in Hamilton et al. (2005). The details are given below, along with calibration and validation procedures and results.

The basis of the model is the matrix of bilateral tourism flows. This matrix is perturbed with scenarios of population growth, economic growth and climate change. The perturbations on the supply side are perturbations on the 'relative attractiveness' of holiday destinations. The perturbations on the demand side are perturbations on the 'number of tourists' from origin countries. For these perturbations, we used the same relationships as we used to construct the bilateral tourism flow matrix.

The model was calibrated against the international arrivals and departures data of 1995 contained in the World Resources Databases (WRI 2000); the data were corrected for typographic errors in the original database. The WRI data are derived from World Tourism Organisation data (e.g. WTO 2003), but presented in a handier format. There are 3 major problems with this dataset. (1) For some countries, the reported data are arrivals and departures for tourism only; for other countries, the data are arrivals and departures for all purposes. It is impossible to correct for this, except for data on Poland and the Czech Republic, which would otherwise be outliers (e.g. in Poland only $12 \%$ of departures are tourists; see Central Statistical Office Poland [2002], available at www.stat.gov.pl/english/ serwis/polska/rocznik11/turyst.htm). (2) The data are total arrivals and total departures; there are no data on the origin of the arrivals or the destination of the departures. We therefore constructed a database on bilateral tourism flows for all pairs of countries. (3) There are missing observations, particularly with regard to departures.

For arrivals, we filled the missing observations with a statistical model:

$$
\begin{aligned}
\ln A_{i}= & \underset{0.97}{5.97}+\underset{0.96}{2.05} \times 10^{-7} \text { Area }_{i}+\underset{0.07}{0.22} T_{i}-\underset{2.21}{7.91} \times 10^{-3} T_{i}^{2} \\
& +\underset{3.03}{7.15} \times 10^{-5} \text { Coast }+\underset{0.09}{0.80} \ln Y_{i} \\
& N=139_{i} R_{\text {adj }}^{2}=0.54
\end{aligned}
$$

where $A$ denotes the number of international arrivals at country $i$, Area is the country's surface area, $T$ is the annual average temperature, Coast is the length of the coastline, and $Y$ is the per capita income in country $i$. The numbers in the main line of the equation are the estimated parameters, the subscripted numbers are the 
standard deviation. This model was the best fit to the observations. The data on per capita income were taken from WRI (2000), supplemented with data from CIA (2002); the data on area and the length of international borders are from CIA (2002); the data on temperature are from New et al. (1999). All data are available at www.uni-hamburg.de/Wiss/FB/15/Sustainability. After filling in missing observations, the total number of tourists increased from 55.2 million to 56.5 million.

For departures, we filled missing observations with a statistical model:

$$
\begin{aligned}
& \ln \frac{D_{i}}{\operatorname{Pop}_{i}}=\underset{17.05}{1.51}-\underset{0.17}{0.18} T_{i}+\underset{16.82}{4.83} \times 10^{-3} T_{i}^{2}-\underset{4.22}{5.56} \times 10^{-2} \text { Border }
\end{aligned}
$$

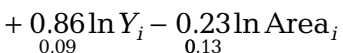

$$
\begin{aligned}
& N=99_{i} R_{\text {adj }}^{2}=0.66
\end{aligned}
$$

where $D$ denotes the number of international departures from country $i$, Pop is population, and Border is the number of land borders. Data on the number of land borders were taken from CIA (2002). This model provided the best fit, but although the fit is better than that for arrivals, the uncertainty about the parameters is greater. The total number of departures was 48.2 million; therefore we scaled up all departures, so that the total number of observed and modelled departures equalled the total number of observed and modelled arrivals; scaling up only the interpolated departures led to distortions, as 99 of the 207 countries do not report departures data.

Bilateral tourism flows were derived as follows. In keeping with the model described below, a 'general attractiveness index' (GAI) for each country was constructed. In a first iteration, the GAI equalled the market share of each country in world tourism. The ratio between predicted and observed tourist arrivals was used to adjust the GAI. The tourists of each country were allocated to other countries according to an index that is proportional to GAI $\times$ distance between the 2 capital cities raised to the power $-1.7 \times 10^{-4}$, so that the model reproduces the 1995 pattern of total departures and arrivals (see Fig. 1). The model is well calibrated, at least in arrivals, as Libya is the only country for which model results and observations deviate graphically; the model predicts that Libya should have a market share of 0.01 to 0.05 , i.e. it should be more popular than it is in reality.

There is only weak empirical evidence that tourists are attracted to places with low or high population densities. Population density is not significant in the variants of Eq. (1) that we estimated; Maddison (2001) reports that British tourists avoid densely populated countries, but Lise \& Tol (2002) and Hamilton (2003) found no significant relationship for Dutch and German tourists. Population growth is therefore assumed to affect international tourism as a proportional increase in departures. As population growth is not uniform over the globe and travel is partly determined by distance, this simple assumption already creates a shift in the pattern of international tourism (Hamilton et al. 2005).

Economic growth is assumed to affect tourism according to Eqs. (1) \& (2). That is, a country becomes more attractive as it grows richer, with an elasticity of 0.80 . A country generates more tourists as it becomes richer, with an elasticity of 0.86 . The population and economic scenarios together produce a marked shift of international tourism towards Asia (Hamilton et al. 2005).

The number of international trips per person is capped at 4 per year, or 1 per season; in 1995, the observed annual maximum was in Bermuda (1.57), Austria (1.55) and Switzerland (1.47); all 3 countries are

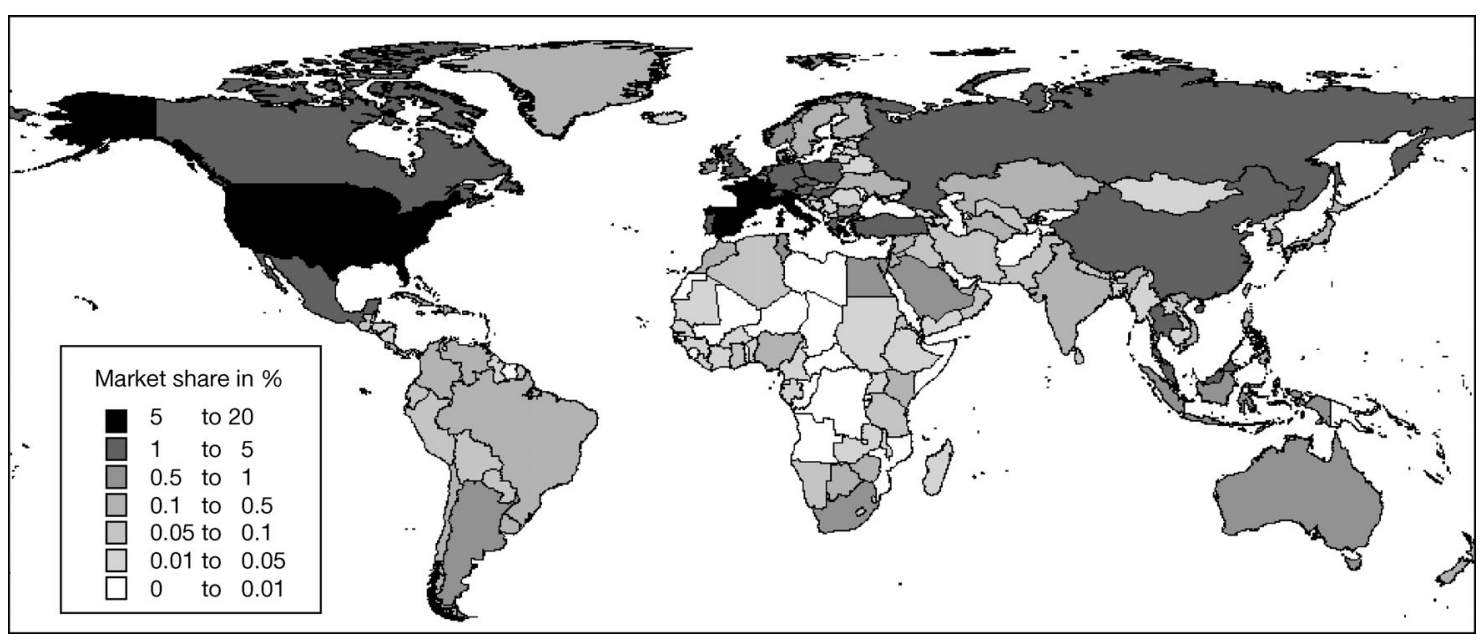

Fig. 1. Share of tourist arrivals per country observed in 1995 

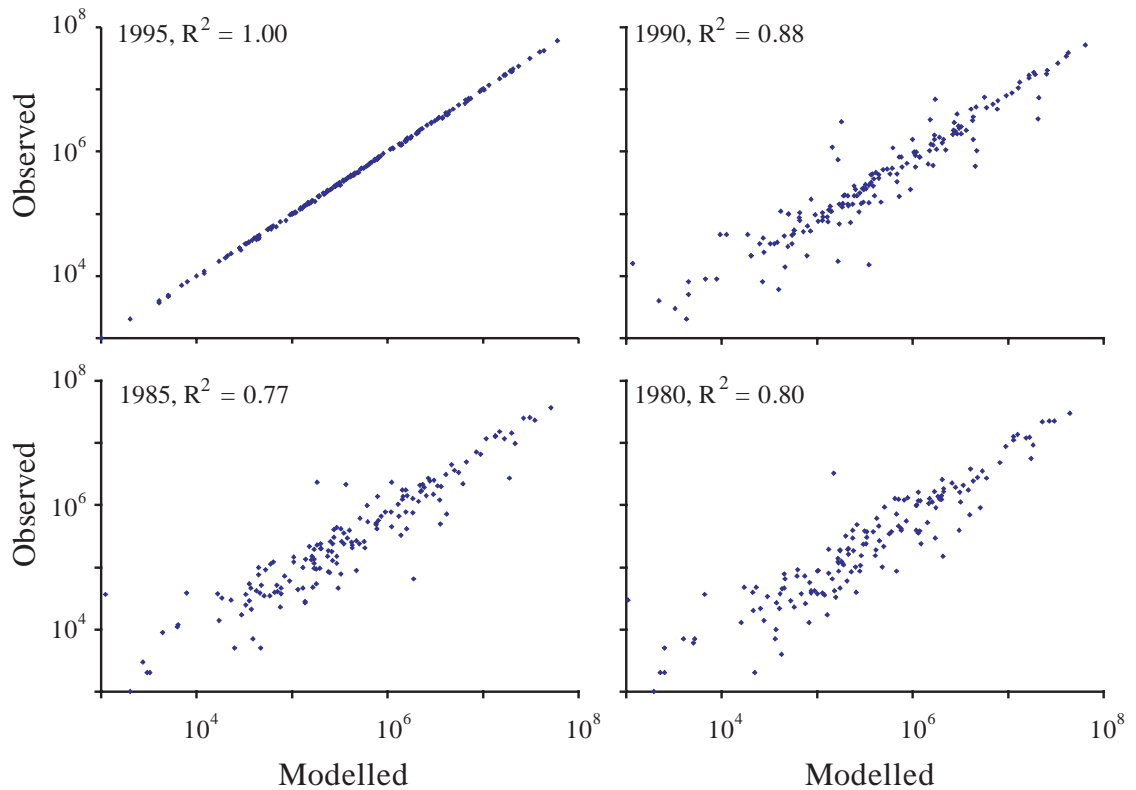

Fig. 2. Observed versus modelled number of tourist arrivals in 207 countries for 1980, 1985, 1990, and 1995
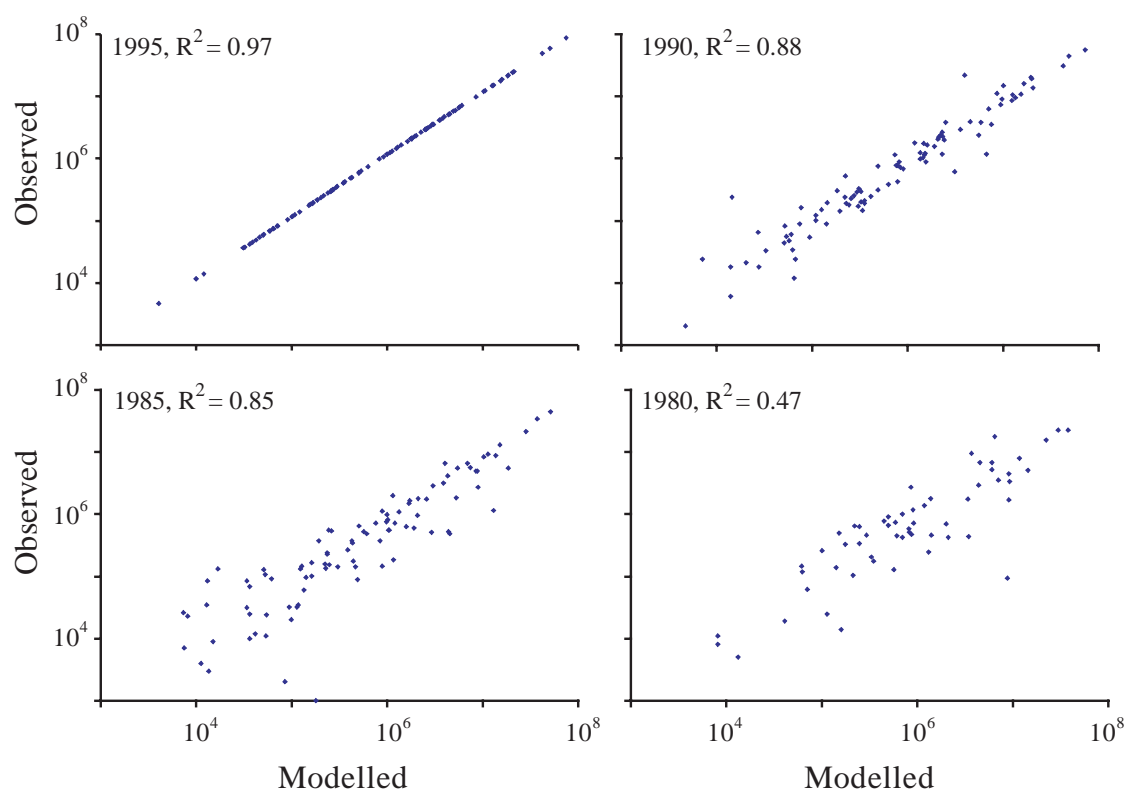

Fig. 3. Observed versus modelled number of tourist departures in 207 countries for 1980, 1985, 1990, and 1995

small and wealthy. The choice of a maximum of 4 international holidays per year is ad hoc.

WRI (2001) presents tourism data for the period $1980-1998 ; 1995$ is the calibration year, and the model operates in time steps of $5 \mathrm{yr}$, so we used the model to 'predict' tourist numbers for the years 1980, 1985, and 1990. Since the model does not have differential equations, time can be readily inverted. There are many missing observations in 1980, so calibrating the model to 1980 and 'predicting' the following 20 yr was not an option. Running the model back in time requires data on population and per capita income. Population data are readily available from WRI (2000), except for a few small or new countries; for these countries, we used the population growth rates of nearby countries and the growth rate of the original country. Per capita income is more problematic. WRI (2000) has many missing observations, which we filled with the national growth rates from the World Bank (2003) website (www.worldbank.org) 'Countries at a glance'; data for the former Yugoslavia were taken from the Penn World Tables, and for North Korea from www.inform.umd.edu/econddata/ WorkPaper/INFORUM/wp97008.pdf.

When model outcomes were compared to past observations, it became apparent that the 1995 cross-section income elasticity of international tourism demand (0.86) is too low. The best fit to the observations of 1980 , 1985 and 1990 is an income elasticity of 2.57. Crouch (1995) reported the results of a meta-analysis of tourism demand. He found an income elasticity of 1.86 , with a standard deviation of 1.78, encompassing both 0.86 and 2.57. The adjustment of the income elasticity was the only adjustment made to the model. Figs. 2 \& 3 compare modelled arrivals and departures to observations. The model reproduces the arrival observations for 1995, the year of calibration, with $\mathrm{R}^{2}=$ 0.9995. The model 'predicts' arrivals in the other years with $R^{2} \geq 0.77$. There are mismatches (see below), but the model reproduces the overall global pattern. For arrivals, most discrepancies between data and model are in Africa and West Asia, where data availability and quality are low. Exceptions are Finland and Japan, which are more popular in reality than in the model, and Australia, which is in fact less popular than the model predicts. For departures, data and model also often disagree for Africa. The Belgians and the Irish travel more than the model predicts, while people from the Nordic countries travel less.

Departures (Fig. 3) are reproduced for 1995 with $\mathrm{R}^{2}=$ 0.97 , and 1990 and 1985 are replicated with $R^{2} \geq 0.85$. For 1980, deviations between model and observations 
are larger: $\mathrm{R}^{2}=0.47$. This is partly due to imperfections in the model, but also because the income data for 1980 are sparse; some countries reported tourist departures, but not income. Moreover, only about half of the modeled departures could be compared to observations. Overall, version 1.1 of the HTM has a reasonable performance in reproducing observations over the 1980-1990 period.

\section{SCENARIO ANALYSIS}

Scenarios of population and economic growth are taken from the 17-region IMAGE 2.2 implementation (IMAGE Team 2001) of the SRES scenarios (Nakicenovic \& Swart 2001). We used the baseline scenario A1B; Hamilton et al. (2005) show results for all 6 SRES scenarios. Scenario A1B assumes moderate population growth and rapid economic growth. More people implies more tourists (Eq. 2). A higher per capita income implies that people travel more (Eq. 2), and that a country becomes relatively more attractive (Eq. 1).

Climate change scenarios are taken from countryspecific output of the COSMIC model (Schlesinger \& Williams 1998). We used the average of the 14 general circulation models (GCMs) in COSMIC as our middle scenario. The effect of climate change follows from Eqs. (1) \& (2), both of which have a quadratic specification. That is, if a cool country becomes warmer, it first attracts more international tourists, until it gets too warm and starts attracting fewer tourists. The turning point lies around $14^{\circ} \mathrm{C}$ (annual $24 \mathrm{~h}$ average). Similarly, if a cool country becomes warmer, fewer domestic tourists spend their holidays abroad until it becomes too warm and more tourists start travelling abroad. The turning point lies at about $18^{\circ} \mathrm{C}$ (annual $24 \mathrm{~h}$ average).

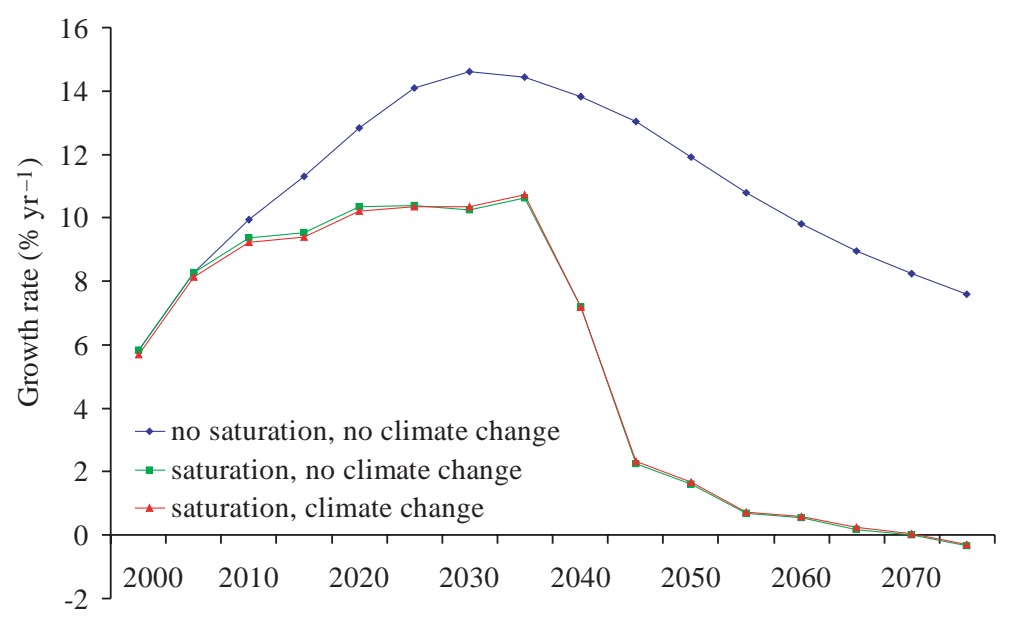

Fig. 4. Growth rate of international tourism according to 3 scenarios
Fig. 4 compares the growth rates of international tourism for 3 scenarios. In the first scenario, tourism demand does not saturate; the growth rate of numbers of international tourists rises to more than $14 \% \mathrm{yr}^{-1}$ in 2025, and then gradually falls as population and economic growth slow; the average number of pleasure trips in foreign countries reaches about 100 per person $\mathrm{yr}^{-1}$ in 2075. As these results are hard to imagine, the second scenario assumes that demand for foreign travel does saturate, at 4 trips $\mathrm{yr}^{-1}$. The number of international tourists rises rapidly in this scenario as well, but not as fast as without saturation; the growth rate is around $10 \% \mathrm{yr}^{-1}$ between 2015 and 2035; these additional tourists are primarily from Asia. After 2035, the market saturates, and growth falls rapidly. In the third scenario, we add climate change. As is shown in Hamilton et al. (2005), climate change perturbs the socio-economic scenario, but does not dominate it. Until 2020, climate change slows the growth of international tourism, as tourists from temperate and cool countries, particularly in Europe, stay within their own country. After 2020, more tourists originate in hot countries, and tourism numbers go up as they seek to spend their holiday at cooler destinations.

Fig. 5 shows the change in departures and arrivals in 2025 for the arbitrary climate change scenario of $1^{\circ} \mathrm{C}$ global warming; this scenario is towards the upper end of the IPCC range (Houghton et al. 2001); it is used for illustrative purposes only. As expected, climate change would lead to a poleward shift of tourism. Countries closer to the poles would become more attractive for tourists. At the same time, those countries would generate less international tourists; these countries would become more attractive to their own citizens as well as to foreigners. Fig. 5 also shows that there will be a shift from lowland to highland tourism; the tourism sectors in Zambia and Zimbabwe, for instance, could benefit greatly from climate change (if other problems are solved).

Fig. 6 plots the change in departures and arrivals due to climate change for 2050, as a function of the initial annual mean temperature. Fig. 6 confirms the messages of Fig. 5. In 2050, climate change would increase the number of arrivals by up to $40 \%$, or reduce arrivals by up to $30 \%$. Departures would increase by up to $10 \%$ or decrease by up to $25 \%$. For most countries, the changes are much smaller. The impact of climate change should be seen in the context of the baseline. Tourism numbers are growing by several percent per year, which is much larger than the effect of climate change. Climate change does not reverse the trend in tourism in any of our projec- 

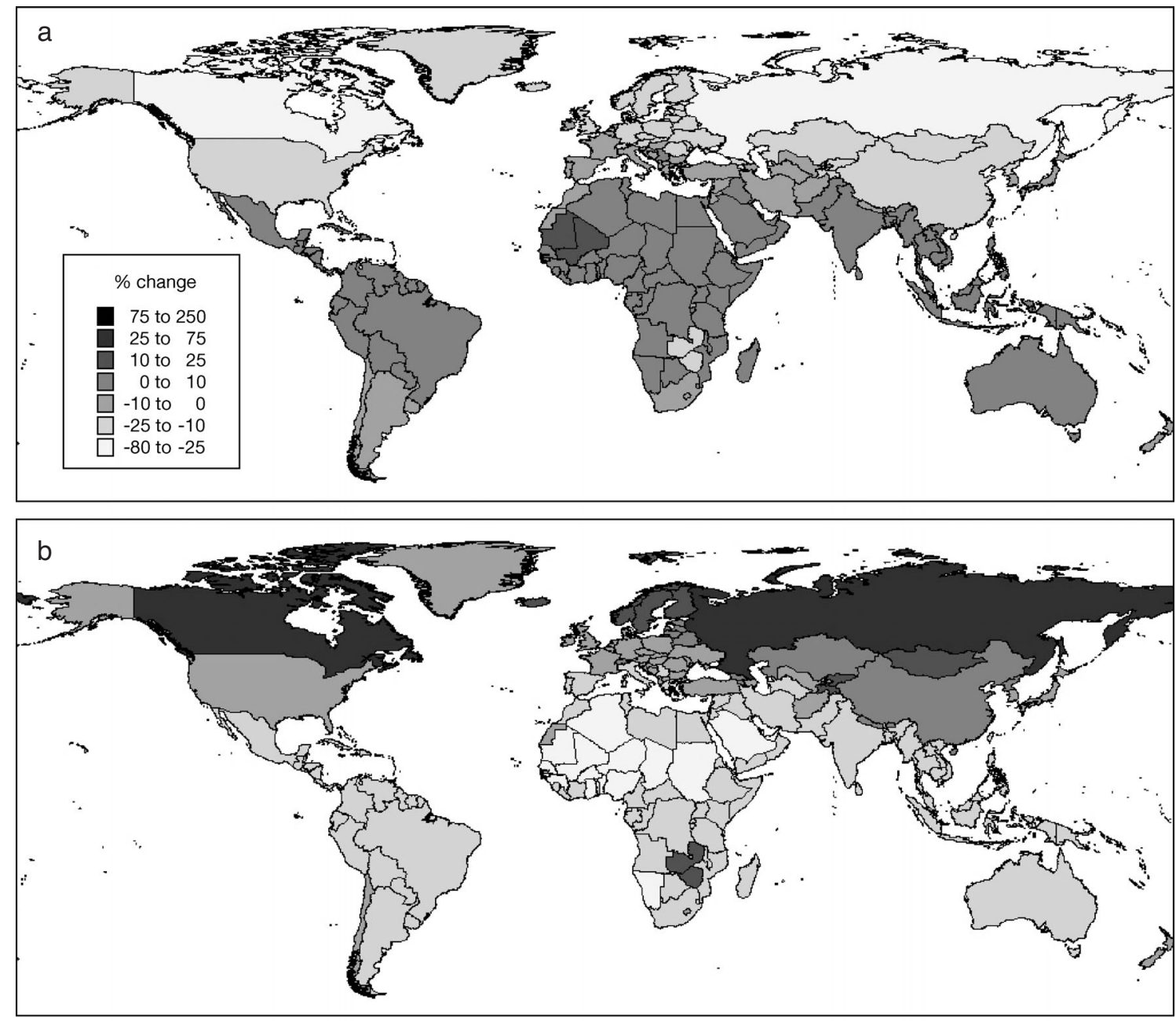

Fig. 5. Change in (a) departures and (b) arrivals as a result of a $1^{\circ} \mathrm{C}$ global warming in 2025

tions; climate change makes tourism grow more or less faster than it would have otherwise. Some of the largest declines (from the baseline) are seen in the Middle East, where nascent leisure resorts may not fare well; pilgrimage, however, is probably robust to climate change.

The distances between the capital cities of the countries of origin and destination are used in the estimation of bilateral tourism flows. The distance travelled also determines energy use and $\mathrm{CO}_{2}$ emissions. We used an emission coefficient of $99 \mathrm{~g} \mathrm{CO}_{2}$ per passenger $\mathrm{km}$ for 2000 (Goessling et al. in press); the coefficient is assumed to fall at $1 \% \mathrm{yr}^{-1}$ because of progress in energy efficiency. Fig. 7 shows the $\mathrm{CO}_{2}$ emitted by international tourists without climate change and the difference induced by climate change, for Scenario $\mathrm{A} 1 \mathrm{~B}$. Without climate change, $\mathrm{CO}_{2}$ emissions increase rapidly at first, in fact even more rapidly than the num- ber of tourists, but stabilises later as the tourism market saturates. At present, international air travel accounts for some $2.4 \%$ of global $\mathrm{CO}_{2}$ emissions (Metz et al. 2001); even with an optimistic rate of technical progress of $1 \%$, this share increases to over $30 \%$ in 2050 in Scenario A1B. If we assume that the demand for tourism saturates at 2 (rather than 4) international trips $\mathrm{yr}^{-1}$, then the share of emissions arising from transport to and from tourism destinations in the total $\mathrm{CO}_{2}$ emissions is capped at $20 \%$ (the emissions scenarios were built without explicit attention to international tourism). With climate change, the upward trend is slightly slower - again largely because the frequent travellers from Northwest Europe stay closer to home. The effect of climate change is in the order of $1 \%$. This effect is similar for the high and low saturation scenarios. Towards 2075, when demand is fully saturated, the impact of climate change beomes zero. 

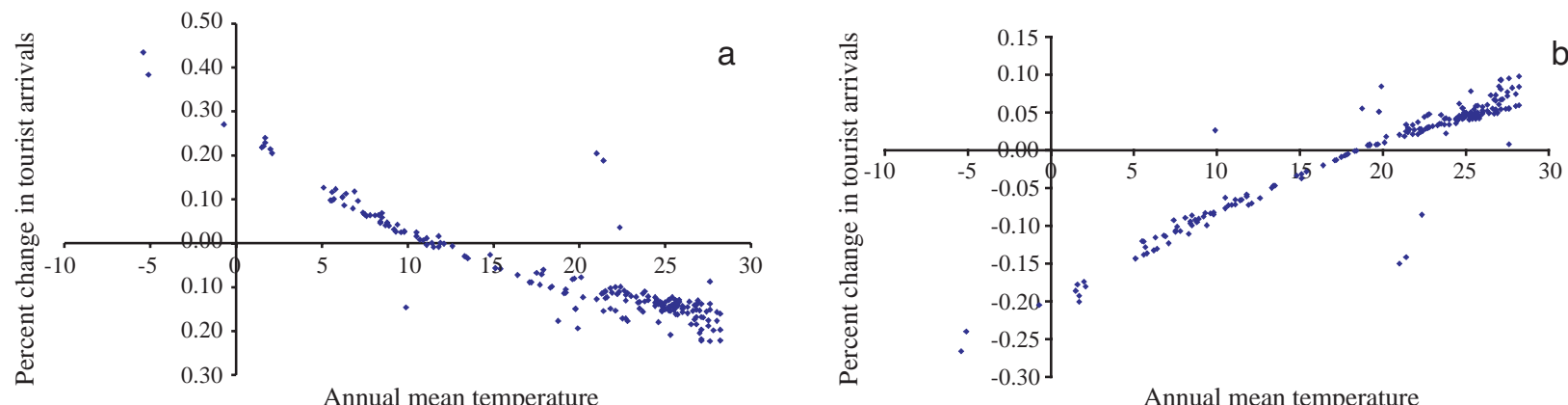

Fig. 6. Change in tourist (a) departures and (b) arrivals in 207 countries in 2050 (\% of tourist numbers without climate change) as a function of annual mean temperature

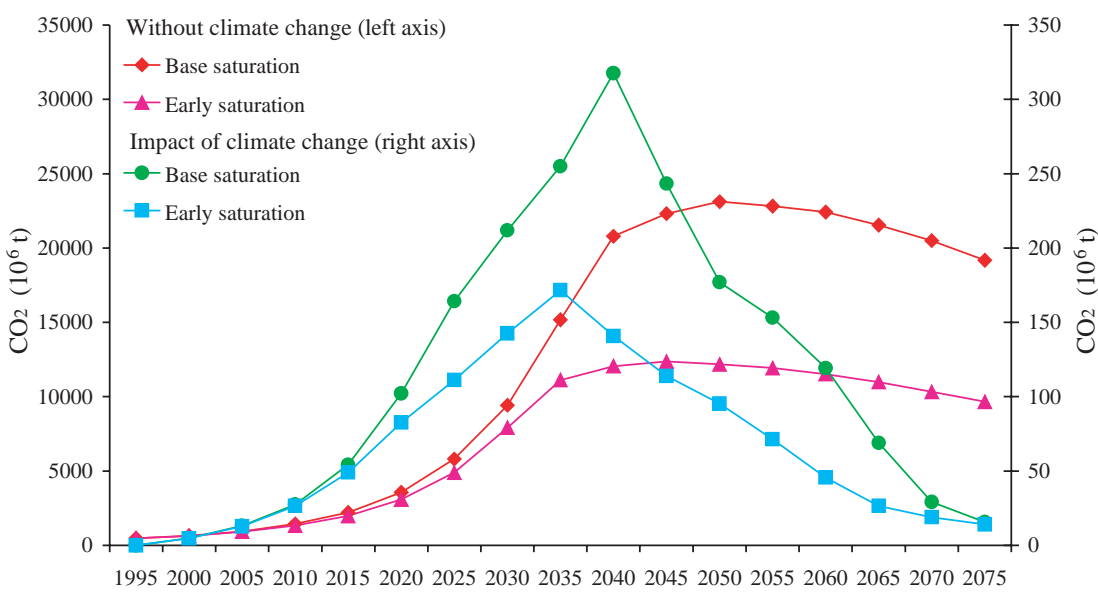

Fig. 7. Total $\mathrm{CO}_{2}$ emitted by international tourism without climate change (left axis) and the difference induced by climate change (right axis); results are for Scenario $\mathrm{A}_{1 \mathrm{~B}}$ in the base scenario, tourism demand saturates at 4 trips $\mathrm{yr}^{-1}$, in the early saturation scenario, demand saturates at 2 trips $\mathrm{yr}^{-1}$

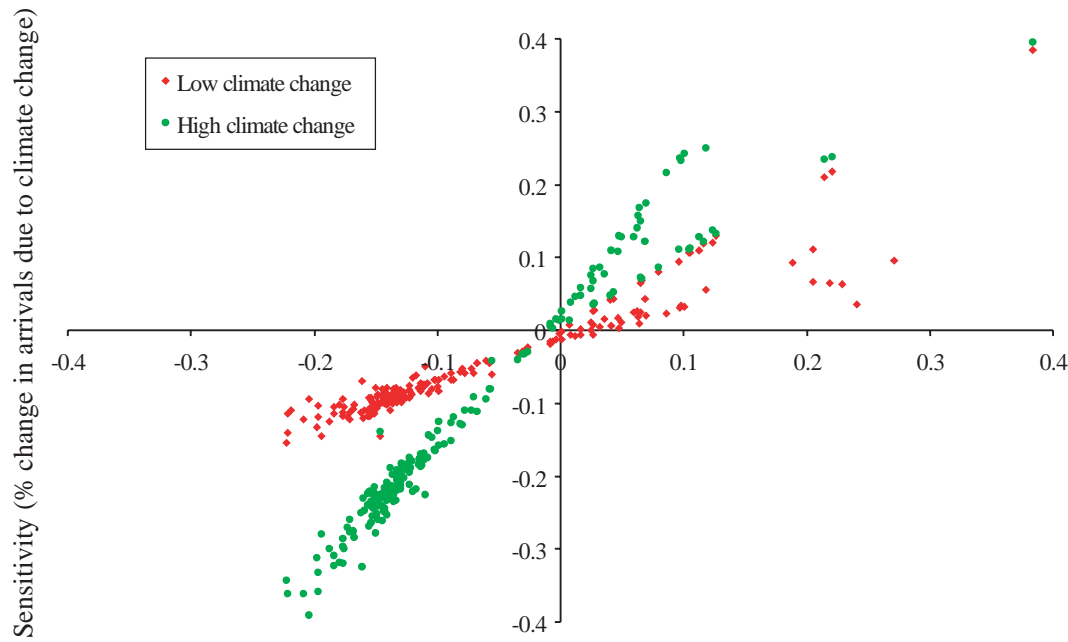

Base (\% change in arrivals due to climate change)

Fig. 8. Climate induced change in tourist arrivals per country in 2050 (Scenario A1B) for medium-level climate change versus high- and low-level climate change

\section{SENSITIVITY ANALYSES}

The model and the results presented above depend on a number of parameters, each of which is uncertain. In Hamilton et al. (2005), we report a sensitivity analysis on the distance parameter, simulating a scenario in which travel would become cheaper over time. This greatly affects travel patterns in Scenario A1B, but does not much affect the impact of climate change. Similarly, we show there that variations in the income elasticity have a large impact on Scenario A1B, but much less so on the relative impact of climate change.

Fig. 8 shows the effects of varying climate change. In the base case, we used the geographic pattern of temperature change that is the average of 14 GCMs at $2 \times \mathrm{CO}_{2}$ (Schlesinger \& Williams 1998). As sensitivity analyses, we used that average plus the standard deviation (and minus half) over the 14 GCMs. This roughly corresponds to varying the climate sensitivity from 2.5 to $1.5^{\circ} \mathrm{C}$ and $4.5^{\circ} \mathrm{C}$, respectively. The results are as expected. Slower climate change leads to lower impacts of climate change, and faster climate change to higher impacts.

Fig. 9 compares the relative impact of climate change on arrivals and departures for tourism demand saturating at 2 and 4 trips $\mathrm{yr}^{-1}$. Although these 2 scenarios considerably differ in absolute numbers of international tourists (cf. Fig. 7), the relative impact of climate change is very similar. The base case assumption of saturation at 
a

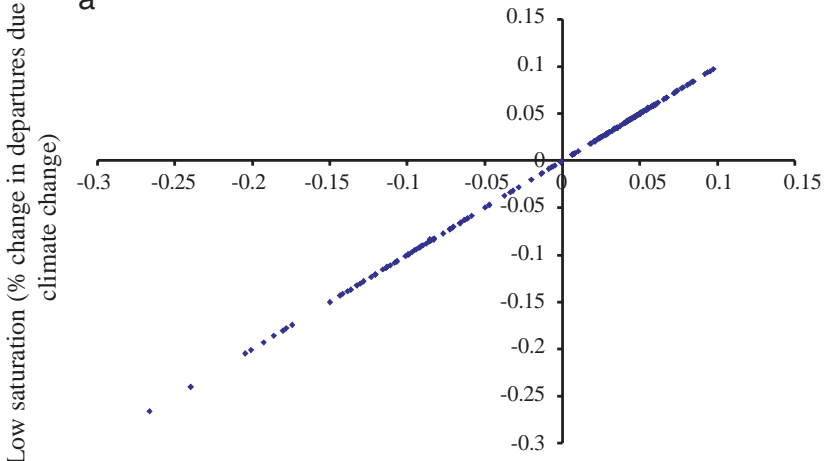

High saturation (\% change in departures due to climate change)

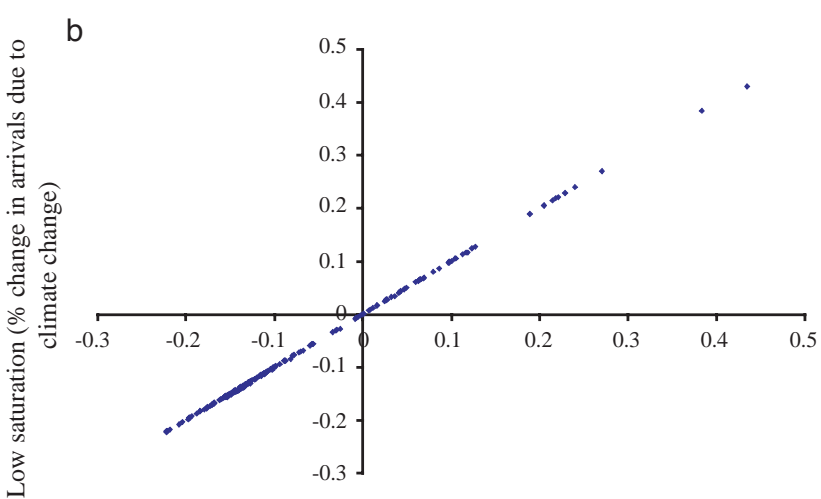

High saturation (\% change in arrivals due to climate change)

Fig. 9. Relative change in the number of (a) departures and (b) arrivals in 207 countries in 2050 (Scenario A1B); base case (demand saturates at 4 trips $\mathrm{yr}^{-1}$ ) compared to alternative (demand saturates at 2 trips $\mathrm{yr}^{-1}$ )

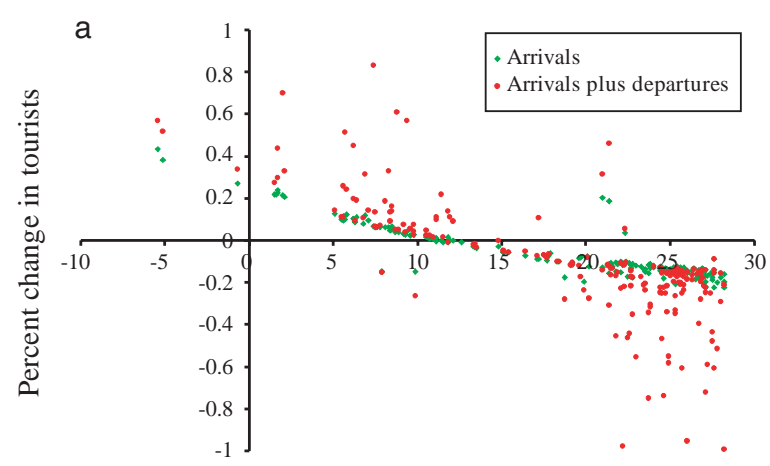

Annual mean temperature

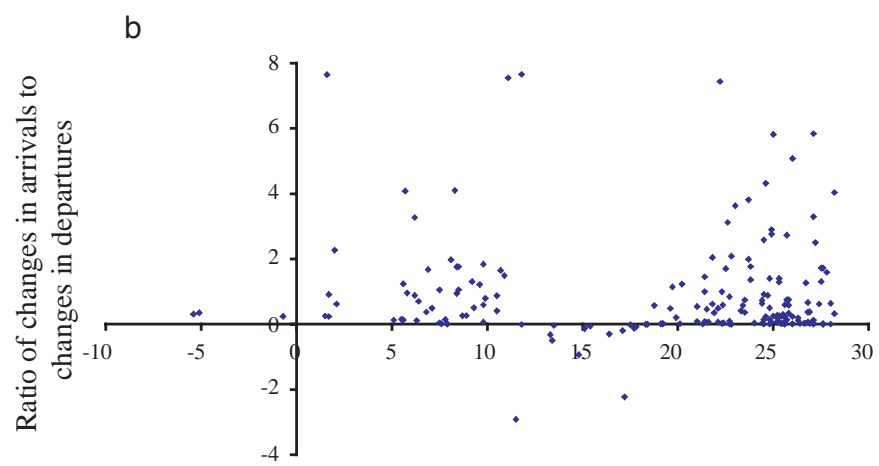

Annual mean temperature

Fig. 10. Change in tourism arrivals in 207 countries in 2050 as a function of annual mean temperature. (a) Arrivals and number of tourists not travelling abroad in \% of tourist numbers without climate change; (b) ratio of the change in arrivals to the number of tourists not travelling abroad

4 trips $\mathrm{yr}^{-1}$ may be ad hoc, but it does not qualitatively influence the results.

The current version of the model is restricted to international tourism. Domestic tourism is not included because of the limited data availability. International departures, however, are included, and responsive to climate change and scenarios. We can therefore calculate the number of people who would have travelled abroad but did not. If we assume that the tourists not travelling abroad add to domestic tourism, we get a better idea of the real changes in tourism. Fig. 10 plots the change in international arrivals as a function of the initial annual mean temperature (as in Fig. 6) and adds the number of tourists not travelling abroad. Almost everywhere, the tourists not travelling abroad amplify the change in tourist arrivals - substantially so in a number of cases. Fig. 10 also shows the ratio of the change in international tourist arrivals and the number of tourists not travelling abroad, again as a function of the initial temperature. In one-third of the cases, the number of tourists not travelling abroad is greater than the change in international tourist arrivals. In onetenth of the cases, the number of tourists not travelling abroad has a different sign than the change in tourist arrivals. This happens in the countries that have an initial temperature between 11 and $18^{\circ} \mathrm{C}$, reflecting the difference in optimal temperature for departures and arrivals (see above).

\section{DISCUSSION AND CONCLUSIONS}

We have presented a simulation model of international tourism, and developed scenarios of changes in international arrivals and departures because of changes in population numbers, per capita income, and climate change. A model like this tests sensitivities rather than making predictions. Although the model does well in predicting out of sample, the validation period is short compared to the 'forecasting' period. 
The model shows that the past growth of international tourism may well continue unabated in the medium term, but will saturate in the long term. The main driver is economic growth, and the growth of international tourism will therefore be concentrated in those regions with the highest economic growth. As high-growth regions are relatively poor at present, saturation will set in later there. Although intercontinental tourism will also grow, future increases in mass tourism are likely to be concentrated close to the countries of origin, e.g. within the high-growth regions of Asia.

Climate change would lead to a gradual shift of tourist destinations towards the poles and up the mountains. Climate change would also imply that the currently dominant group of international touristssun and beach lovers from Western Europe-would travel less far, or even stay in their home country, implying a fall of total international tourist numbers (relative to the baseline without climate change). The reverse is true for warmer countries; not only would these countries attract less foreign tourists, domestic tourists would be inclined to travel abroad for their holidays. The pattern of international tourism-towards higher latitudes and altitudes - found by Hamilton et al. (2005) is amplified by shifts in domestic tourism: Higher (lower) latitudes and altitudes would become more (less) attractive to international and domestic tourists alike.

Nonetheless, the changes induced by climate change are generally much smaller than the changes due to population and economic growth. Again in comparison with Hamilton et al. (2005), the saturation of tourism demand introduced in this study makes the baseline even more important relative to the impact of climate change.

A reduction in international tourism implies a reduction in international travel and a reduction in greenhouse gas emissions from international travel. This is a negative feedback on the emission scenarios, but we find that emissions from international tourist travel fall by less than $1 \%$ because of climate change.

The model described in this study is, to our knowledge, one of its kind. As for all early models, it has limitations. Although the model is reasonably good at reproducing current and past patterns of international tourism, long-term and global studies of tourism demand are rare-and the empirical basis of the model is therefore weak. This is even truer for the effects of climate change on tourist destination choice, where the model is based on only a few studies from a limited set of similar countries. Domestic tourism is modelled as a residual of international tourism. The projections neglect the fact that changes in preferences, age structure, working hours and lifestyles would also affect tourist behaviour. Demand saturation is included in an ad hoc manner. The spatial resolution (national) of the model is crude, as is the temporal resolution (annual). A seasonal resolution would allow for the separate analysis of sun and snow seekers, and would allow tourists to shift their holidays not only in space (as they do in the current model) but also in time (from summer to spring and autumn). The model does not extend beyond tourist numbers. Improving on all this is deferred to future research. The results presented here demonstrate that this is a fruitful line of research.

Acknowledgements. Comments by D. Scott of Climate Research, S. Smith of the Pacific Northwest National Laboratory, and several anonymous referees helped to improve the manuscript. The CEC DG Research through the DINAS-Coast project (EVK2-2000-22024), the US National Science Foundation through the Center for Integrated Study of the Human Dimensions of Global Change (SBR-9521914) and the Michael Otto Foundation for Environmental Protection provided financial support. All errors and opinions are ours.

\section{LITERATURE CITED}

Abegg B (1996) Klimaänderung und Tourismus-Klimafolgenforschung am Beispiel des Wintertourismus in den Schweizer Alpen. vdf Hochschuleverlag an der ETH, Zurich

Aguiló E, Alegre J, Sard M (2005) The persistence of the sun and sand tourism model. Tourism Manage 26:219-231

Amelung B, Viner D (in press) The vulnerability to climate change of the Mediterranean as a tourist destination. In: Amelung B, Blazejczyk K, Matzarakis A, Viner D (eds) Climate change and tourism: assessment and coping strategies. Kluwer Academic Publishers, Dordrecht

Central Statistical Office Poland (2002) Tourism statistics. Central Statistical Office of Poland, Warsaw (available at: www.stat.gov.pl/english/serwis/polska/rocznik11/turyst. $\mathrm{htm})$

CIA (2002) The world factbook 2002. Central Intelligence Agency, Washington, DC (available at: www.cia.gov/cia/ publications/factbook)

Craig-Smith S, Ruhanen L (2005) Implications of climate change on tourism in Oceania. In: Hall CM, Highham $\mathrm{J}$ (eds) Tourism, recreation and climate change. Channel View Publications, Clevedon, p 192-207

Crouch GI (1995) A meta-analysis of tourism demand. Ann Tourism Res 22:103-118

Goessling S (2002) Global environmental consequences of tourism. Global Environ Change 12:283-302

Goessling S, Peeters P, Ceron J, Dubois G, Patterson T, Richardson RB (in press) The eco-efficiency of tourism. Ecol Econ

Hamilton JM (2003) Climate and the destination choice of German tourists. Working paper FNU-15, Research Unit Sustainability and Global Change, Hamburg University and Centre for Marine and Atmospheric Science, Hamburg

Hamilton JM, Tol RSJ (2004) The impacts of climate change on tourism and recreation. Working paper FNU-52, Research Unit Sustainability and Global Change, Hamburg University and Centre for Marine and Atmospheric Science, Hamburg 
Hamilton JM, Maddison DJ, Tol RSJ (2005) Climate change and international tourism: a simulation study. Global Environ Change 15:253-266

Houghton JT, Ding Y, Griggs DJ, Noguer M, van der Linden PJ, Xiaosu D (eds) (2001) Climate change 2001: the scientific basis - contribution of Working Group I to the Third Assessment Report of the Intergovernmental Panel on Climate Change. Cambridge University Press, Cambridge

IMAGE Team (2001) The IMAGE 2.2 implementation of the SRES scenarios: a comprehensive analysis of emissions, climate change and impacts in the 21st century. RIVM CD-ROM Publication 481508018. National Institute for Public Health and the Environment, Bilthoven

Lise W, Tol RSJ (2002) Impact of climate on tourism demand. Clim Change 55:429-449

Maddison DJ (2001) In search of warmer climates? The impact of climate change on flows of British tourists. Clim Change 49:193-208

Metz B, Davidson O, Swart R, Pan J (eds) (2001) Climate change 2001: mitigation - contribution of Working Group III to the Third Assessment Report of the Intergovernmental Panel on Climate Change. Cambridge University Press, Cambridge

Nakicenovic N, Swart RJ (2001) IPCC special report on emissions scenarios. Cambridge University Press, Cambridge

New M, Hulme M, Jones PD (1999) Representing twentieth century space-time climate variability. Part 1. Development of a 1961-90 mean monthly terrestrial climatology. J Clim 12:829-856

Perry A (2005) The Mediterranean: How can the world's most popular and successful tourist destination adapt to a changing climate? In: Hall CM, Highham J (eds) Tourism, recreation and climate change. Channel View Publications, Clevedon, p 86-96

Editorial responsibility: Daniel Scott, Ontario, Canada
Richardson RB, Loomis JB (2004) Adaptive recreation planning and climate change: a contingent visitation approach. Ecol Econ 50:83-99

Schlesinger ME, Williams LJ (1998) COSMIC 1.1 countryspecific model for intertemporal climate. Electric Power Research Institute, Palo Alto, CA

Scott D, McBoyle G (2001) Using a 'tourism climate index' to examine the implications of climate change for climate as a tourism resource. In: Matzarakis A, de Freitas CR (eds) Proc 1st Int Workshop Climate, Tourism and Recreation, Porto Carras, Neos Marmaras, Halkidiki, Greece, 5 to 10 October 2001. International Society of Biometeorology (available at: www.mif.uni-freiburg.de/isb/ws/report.htm)

Scott D, McBoyle G, Schwartzentruber M (2004) Climate change and the distribution of climatic resources for tourism in North America. Clim Res 27:105-117

Scott D, McBoyle G, Wall G (2005) The evolution of the climate change issue in the tourism sector. In: Hall CM, Highham J (eds) Tourism, recreation and climate change. Channel View Publications, Clevedon, p 192-207

Smith JB, Schellnhuber HJ, Mirza MMQ, Fankhauser S and 9 others (2001) Vulnerability to climate change and reasons for concern: a synthesis. In: McCarthy JJ, Canziani OF, Leary NA, Dokken DJ, White KS (eds) Climate change 2001: impacts, adaptation, and vulnerability. Cambridge University Press, Cambridge, p 913-967

Witt SF, Witt CA (1995) Forecasting tourism demand: a review of empirical research. Int J Forecast 11:447-475

World Bank (2003) Countries at a glance. World Bank Group, Washington, DC (available at: www.worldbank.org)

WRI (2000) World resources database 2000-2001. World Resources Institute, Washington, DC

WTO (2003) Yearbook of tourism statistics. World Tourism Organisation, Madrid

Submitted: February 7, 2005; Accepted: July 2, 2005 Proofs received from author(s): October 5, 2005 